\title{
Inhibition of Metal Dusting using Thermal Spray Coatings and Laser Treatment
}

\author{
K.T. Voisey ${ }^{1}$, Z. Liu \& F.H.Stott \\ Corrosion and Protection Centre \\ School of Materials \\ The University of Manchester \\ UK \\ 1: corresponding author, now at \\ School of Mechanical, Materials and Manufacturing Engineering \\ University of Nottingham \\ University Park \\ Nottingham NG7 2RD \\ tel: +441159514139 \\ fax: +441159513800 \\ email: katy.voisey@nottingham.ac.uk
}




\section{Abstract}

Alloy 600 and Alloy $800 \mathrm{H}$ are susceptible to metal dusting. Both alloys were thermally sprayed with two different corrosion resistant coatings: Ni50Cr and Ni31Cr11Al0.6Y. Laser remelting was used to enhance further the effectiveness of these coatings to resist metal dusting by eliminating interconnected porosity and improving coating adhesion.

Uncoated, coated and laser-treated coated samples of Alloy 600 and Alloy $800 \mathrm{H}$ were exposed to a mixed gas atmosphere $\left(20 \% \mathrm{H}_{2}, 80 \% \mathrm{CO}\right.$ at $\left.650^{\circ} \mathrm{C}\right)$. Samples were examined in plan and cross-section using optical and scanning electron microscopy, electron probe microanalysis and X-ray diffraction. The extent of carbon deposition was tracked by mass difference measurements at intervals during exposure.

The thermally sprayed coatings enhanced metal dusting resistance by acting as physical barriers to carbon ingress. The NiCrAlY coating performed well on both substrates. The NiCr coating itself underwent metal dusting and spalled from Alloy $800 \mathrm{H}$ due partly to CTE mis-match stresses. Laser treatment of both coatings successfully eliminated interconnected porosity and hence enhanced metal dusting resistance.

\section{Keywords}

Metal dusting; Laser alloying; Laser treatment of coatings; Thermal spray coatings; Corrosion prevention; corrosion resistant coatings; 


\section{Introduction}

Metal dusting is a catastrophic carburisation process that occurs in the temperature range: $450^{\circ} \mathrm{C}$ to $850^{\circ} \mathrm{C}$ in atmospheres where the notional carbon activity, $\mathrm{a}_{\mathrm{c}},>1$, conditions in many steam reformers, methanol plants and other chemical processes that use synthesis gas $\left(\mathrm{H}_{2}+\mathrm{CO}\right)$. Metal dusting causes disintegration of the metal into a dust of graphite and metal particles. This metal loss decreases component lifetimes, ultimately leading to failure [1]. Also, the build up of coke during the process requires regular decoking cycles, with the associated expense of production downtime.

Fundamental research into metal dusting was initiated by Hochmann [2-4] who concentrated on iron-based alloys. Extensive work in this area was later carried out by Grabke et al. [5-8] .Recently, Szakalos has presented refinements to the mechanisms of metal dusting which include the role of oxidation [9-11]. Review papers by Grabke [12] and Jones and Baumert [13] provide thorough summaries of the subject of metal dusting.

Theoretically, any material able to dissolve carbon may succumb to metal dusting [14]. However, due to their engineering importance, research into metal dusting usually concentrates on iron- and nickel-base alloys [13]. The mechanisms of metal dusting, as generally reported $[4,8,11,15,16]$, are summarised briefly as follows. In iron-base alloys, adsorbed carbon saturates the metal surface and forms cementite. The presence of cementite restricts carbon ingress. Subsequently, the metastable cementite decomposes into graphite and metal particles. In nickel-base alloys, a carbide intermediary is not required. Graphite forms directly from the carbon-saturated alloy and then grows into the alloy, causing disintegration. Both mechanisms generate small metallic particles that can catalyse coke formation and the growth of carbon filaments. 
Suppression of metal dusting can be achieved by the formation and retention of an oxide scale, usually alumina or chromia, that provides a barrier to carbon ingress [17]. Such protection can be facilitated by coating the alloy with a material that contains a sufficient proportion of scale-forming elements. Due to its greater stability in high carbon activity and low oxygen partial pressure environments, alumina rather than chromia is the preferred protective scale [18]. As summarised by Bayer [18], aluminium-rich diffusion coatings can improve metal dusting resistance [19-21]. Two-stage diffusion coatings, that contain chromium or chromium and silicon in addition to aluminium, have been effective against high-temperature carburisation [22, 23] and may also inhibit metal dusting [18]. However, the slow kinetics of alumina formation at metal dusting temperatures limit the effectiveness of aluminium-based coatings. This has led to the use of chromium-based coatings, where the faster kinetics of chromia formation can establish a protective scale more rapidly [1].

Thermally sprayed coatings have previously been shown to improve metal dusting resistance. A $\gamma$-TiAl high velocity oxy-fuel (HVOF) coating has been used to protect Alloy 800 from metal dusting [24, 25], a HVOF coating of NiAl has also been used to suppress carburisation of HP steel [26] and a HVOF Ni50Cr coating has successfully decreased metal dusting of a $1 \mathrm{Cr}-0.5 \mathrm{Mo}$ steel.

Thermally sprayed coatings, such as the HVOF coatings described above and the plasma sprayed coatings used in the present work, contain inhomogeneities such as inter-splat porosity, unmelted particles and micro-cracks [26-28]. The presence of interconnected porosity is of prime concern as it limits the effectiveness of the barrier provided by the coating. Laser treatment can seal the coating by remelting either a thin surface layer or 
the entire thickness of the coating, hence eliminating porosity in the treated region [29, 30]. The corrosion resistance of various thermal sprayed coatings has been improved by such laser treatment [28, 31-34]; however, the technique has not previously been applied to the problem of metal dusting.

Adhesion of thermally sprayed coatings is primarily achieved by mechanical interlocking. For metal/metal systems, adhesion may be enhanced by diffusion across the interface. However, the substrate/coating interface generally remains relatively weak. Due to the combination of the considerable residual stresses present in thermally sprayed coatings [35] and a relatively weak interface, such coatings are susceptible to spallation [1, 25, 26]. Laser remelting of the entire coating thickness can improve coating adhesion since, by remelting a thin layer of the substrate as well as the coating, the original interface is removed and replaced by metallurgical bonding on resolidification [28, 33, 36, 37].

The composition and phases present in the laser treated layer may change during the laser treatment process. Generally, it is preferable to have as little alloying of the coating and substrate as possible, so that the protective properties of the coating material are not degraded by dilution. However, some coating-substrate alloying is unavoidable if the strength of the original coating/substrate interface is to be increased by metallic bonding. Also, rapid solidification, such as that encountered in laser processing, can result in phases of non-equilibrium compositions due to extended solid solubility, also known as solute trapping [38, 39].

The current work aims to improve the metal dusting resistance of Alloy $800 \mathrm{H}$ and Alloy 600 using plasma sprayed coatings. The effectiveness of $\mathrm{Ni50Cr}$ and 
Ni31Cr11Al0.6Y coatings have been examined in both the as-sprayed and laser-treated conditions.

\section{Experimental Methods}

\section{Materials}

The compositions of the Alloy $800 \mathrm{H}$ and Alloy 600 used in this work are shown in Table 1. Cubic samples of $\sim 1 \mathrm{~cm}^{3}$ were cut from supplied plates of the alloys. The as-received faces of the samples were removed using 240 grit $\mathrm{SiC}$ grinding paper. Each face of the uncoated, non-laser treated reference samples was ground to a 600 grit finish prior to exposure.

The two plasma sprayed coatings, $\mathrm{Ni} 50 \mathrm{Cr}$ and Ni31Cr11Al0.6Y, were chosen as they are chromia- and alumina-formers respectively, according to the criteria of Schueler and Schillmoller for establishment of protective oxide scales [13]. The NiCrAlY coating was formed using a standard off-the-shelf powder of the same composition, while the $\mathrm{NiCr}$ coating was formed from a mixture of $\mathrm{Ni} 20 \mathrm{Cr}$ and $\mathrm{Cr}$ powders. Vacuum plasma spraying of the coatings was carried out at Plasma and Thermal Coatings Ltd, Newport, South Wales. Samples were grit blasted prior to coating to enhance coating adhesion. Cubic samples, $\sim 1 \mathrm{~cm}^{3}$, were coated on all sides with a nominal coating thickness of $150 \mu \mathrm{m}$.

Small samples with sharp edges are not generally suitable for plasma spraying due to edge effects which limit coating performance. However, here the sample size was limited by the dimensions of the furnace and quartz reaction tube used in this work. Metal dusting experiments are very sensitive to the conditions reached in the reaction tube. This 
experimental set up was used to ensure that results could be directly compared with previous work within the same project.

The coatings used in this work have higher levels of unmelted particles, and hence inter-connected porosity, than would generally be expected in metallic vacuum sprayed coatings. The coating conditions were not optimised for the samples, however the coatings used retain the general features of metallic vacuum sprayed coatings which are relevant to laser treatment (inter-connected porosity).

NiCrAlY coatings generally have a $\gamma($ fcc $\mathrm{Ni}$ matrix $)+\beta($ intermetallic NiAl $)$ structure. This was not the case for the coating in this work. XRD in plan (Figure 1) indicated the presence of a bcc $(\alpha)$ structure, as well as the expected $(\gamma+\beta)$ phases, although the peaks corresponding to the $\gamma$ phase were relatively small. $\mathrm{Cr}$ has a bcc structure, and the high $\mathrm{Cr}$ content of the coating appears to stabilise a bcc matrix. XRD revealed two phases in the as-sprayed $\mathrm{NiCr}$ coating: an austenitic fcc phase and a bcc phase (Figure 2). Examination of the Ni-Cr binary phase diagram [40] shows that a two-phase structure is expected, an Ni-rich fcc phase and a Cr-rich bcc phase.

\section{Laser Treatment}

Laser treatment was carried out using a $2 \mathrm{~kW} \mathrm{CO}$ continuous wave slab laser (ROFIN DC020). X-Y sample motion was achieved by a computer-controlled table. Flowing argon was the shield gas used to protect the sample surface from (excessive) oxidation during laser treatment.

A $~ 1.5 \mathrm{~mm}$ beam diameter, with an advance of $0.3 \mathrm{~mm}$ between successive tracks, was used. The resulting $80 \%$ overlap ensured a uniform melt depth. The laser raster was 
restricted to the sample surface. Laser processing parameters (Table 2) to melt the entire coating thickness were determined by a series of preliminary trials.

The XRD spectra in plan from the laser-treated NiCrAlY coatings on Alloys $800 \mathrm{H}$ and 600 were essentially identical to each other (Figure 1). Due to incomplete shielding during laser processing, some laser-induced oxides were formed. The spectra revealed that most of the oxide was $\alpha-\mathrm{Al}_{2} \mathrm{O}_{3}$. Peaks also matching more complex aluminium/yttrium/niobium oxides were detected, although it was not possible to determine exactly which oxides were present due to the relatively small peak sizes and close similarities between the spectra of the various oxides. Two small peaks at $2 \Theta=18^{\circ}$ and $30^{\circ}$ indicated the presence of a spinel structure; however it was not possible to identify which particular spinel was present. Peaks corresponding to $\alpha$ and $\gamma$ phases were again seen, although the $\gamma$ peaks were more prominent than the $\alpha$ peaks. This was attributed to dilution of the coating by alloying with the austenitic $(\gamma)$ substrate, and consequent stabilisation of the $\gamma$ phase at the expense of the $\mathrm{Cr}$-rich $\alpha$ phase.

Most of the main peaks in the XRD spectrum for the laser treated NiCr coating on Alloy 600 (Figure 2) could be attributed to either $\mathrm{Cr}_{2} \mathrm{O}_{3}$ or an austenitic structure. A small peak at $2 \Theta=18^{\circ}$ may be due to a spinel phase; however, several other peaks were missing from the spinel pattern, suggesting that, if spinel was present, it was only in a small quantity. More spinel lines were present for the laser-treated $\mathrm{NiCr}$ coating on Alloy $800 \mathrm{H}$ where austenite and $\mathrm{Cr}_{2} \mathrm{O}_{3}$ were again the main phases. This is due to the higher $\mathrm{Fe}$ content of Alloy $800 \mathrm{H}$ compared to Alloy 600. For the coatings on both substrate alloys, the bcc, Cr-rich phase was not visible in the XRD patterns after laser treatment. This is attributed to a combination of two effects: stabilisation of the fcc austenitic phase due to 
alloying with $\mathrm{Ni}$ and $\mathrm{Fe}$ from the substrate and depletion of the bcc stabilising $\mathrm{Cr}$ from the laser treated layer by formation of laser-induced oxides.

\section{Exposure to the Mixed Gas Environment}

Samples were located in quartz boats during exposure, each boat held one sample. These were ultrasonically cleaned in ethanol and dried by a hot air blast and, then, inserted into the horizontal reaction tube and exposed to a mixed-gas atmosphere of $20 \% \mathrm{H}_{2}$ and $80 \%$ $\mathrm{CO}$ at $650^{\circ} \mathrm{C}$ with a flow rate of $50 \mathrm{~cm}^{3} \mathrm{~min}^{-1}$. A double-walled, quartz reaction tube ensured that the reaction gases were mixed and raised to temperature before reaching the samples. The tube was heated to the required temperature in flowing $\mathrm{H}_{2}$, then $\mathrm{CO}$ was mixed with the flowing $\mathrm{H}_{2}$. After the required exposure time, the $\mathrm{CO}$ supply was shut off and the tube cooled to room temperature in flowing $\mathrm{H}_{2}$.

\section{Sample Examination}

At intervals, the test was interrupted, the furnace was cooled and the samples were removed; some were examined by optical and scanning electron microscopy (SEM). To examine the carbon on whole (non-sectioned) samples by SEM, loose, non-adherent carbon deposits were removed with an air blast, leaving only adherent deposits for examination. Selected samples were examined in cross-section by electron probe microanalysis (EPMA) and X-ray diffraction (XRD).

\section{Mass Difference Measurements}

Each sample and quartz boat was weighed prior to exposure, with a Sartorius microbalance that, by repeated measurements and control samples, can measure to $\pm 250 \mu \mathrm{g}$. The quartz boats, still containing the samples, were removed from the furnace 
and weighed after the various exposure times. During weighing, samples were not removed from the quartz boats, nor was any carbon deposit cleaned from the samples. The increase in mass was, therefore, a measure of the total mass of carbon deposited on each quartz boat and the specimens, plus any oxygen taken up to form oxide on the sample surface. Each mass difference data point presented for uncoated Alloy $800 \mathrm{H}$ represents a different sample (Figure 3). For other sample types, the data points represent the mass differences measured at intervals during the exposure, one sample being used for each data series.

\section{Results}

\section{Alloy 800H}

Uncoated Alloy $800 \mathrm{H}$ rapidly underwent severe metal dusting (Figure 4). Carbon deposition and filament growth occurred within $100 \mathrm{~h}$; further exposure led to extensive metal dusting, as was evident from the growth of carbon filaments.

The as-deposited NiCrAlY had a markedly lower mass gain than the uncoated Alloy $800 \mathrm{H}$ (Figure 3). Deposited carbon started to blacken the sample surface within $50 \mathrm{~h}$. Further exposure led to a gradual increase in the amount of carbon deposition, but no metal dusting (Figure 5a), i.e. growth of carbon filaments was apparent on the coating before the end of the test at $1200 \mathrm{~h}$.

Examination of the exposed NiCrAlY-coated sample in cross-section showed some degradation of the outermost part of the coating (Figure 5b). However, EPMA revealed no enrichment in carbon or oxygen at the coating surface. XRD again showed the bcc- $\alpha$ and fcc- $\gamma$ phases as in the as-sprayed coating. In addition, $\mathrm{Ni}_{3} \mathrm{Al}\left(\gamma^{\prime}\right)$, which was not 
initially present, was detected. The $\beta(\mathrm{NiAl})$ phase which was in the as-sprayed coating was no longer detected. No oxides were detected.

While the NiCrAlY coating itself did not undergo metal dusting, coating failure of NiCrAlY-coated Alloy $800 \mathrm{H}$ still occurred during exposure to the mixed gas environment. A crack was observed after $\sim 500 \mathrm{~h}$, further exposure led to coating spallation from the crack site (Figure 6a). EPMA examination of a cross-section of this sample revealed localised penetration of carbon through interconnected porosity within the coating (Figure 6b).

As-deposited NiCr-coated Alloy $800 \mathrm{H}$ failed by coating spallation within $50 \mathrm{~h}$ (Figure 7a). The coating was blackened by carbon, while metal dusting had initiated on the exposed alloy substrate. Exposure of a NiCr-coated Alloy $800 \mathrm{H}$ sample to $650^{\circ} \mathrm{C}$ for $50 \mathrm{~h}$ in flowing argon did not induce coating spallation.

SEM examination of a non-debonded region of the coated sample showed that the $\mathrm{NiCr}$ coating was covered by extensive carbon deposits, typical of metal dusting (Figure 7b). EPMA mapping showed carbon and oxygen enrichment in the outermost $\sim 50 \mu \mathrm{m}$ of the coating after $100 \mathrm{~h}$ (Figure 8). The XRD (Figure 9) spectrum obtained from a non-debonded part of the coated sample showed the presence of an austenitic phase, graphite and chromia. $\mathrm{Cr}_{23} \mathrm{C}_{6}$ may also have been present; however this could not be confirmed as the peak size was not significantly larger than the background noise. The Cr-rich bcc phase in the as-sprayed $\mathrm{NiCr}$ coating was no longer detected.

Comparison of as-sprayed and exposed NiCr-coated Alloy $800 \mathrm{H}$ revealed a shift in the austenitic peaks of the exposed samples to higher $2 \Theta$ angles, indicating a smaller lattice parameter (Figure 9). 


\section{Alloy 600}

Metal dusting was not initiated on Alloy 600 until after $~ 1000$ h exposure (Figure 10a).

An initial, step-increase in mass, followed by a period of steady but slow increase was observed in each case for the coated samples (Figure 10b). While the coated samples gave larger total mass gains, the rates of mass gain were actually less than for the noncoated samples during exposure from $\sim 200 \mathrm{~h}$ onwards. Neither as-deposited NiCrAlY-coated samples nor as-deposited NiCr-coated samples exhibited any carbon filament growth before the test ended at $800 \mathrm{~h}$. However, examination in cross-section revealed that the $\mathrm{NiCr}$ coating had itself undergone metal dusting. A second pair of coated samples showed localized initiation of metal dusting after $579 \mathrm{~h}$. Further exposure to $1752 \mathrm{~h}$ produced extensive carbon filament growth, although this was still restricted to discrete sites. Metal dusting was limited to one corner of the NiCrAlY-coated sample, the rest of the sample surface was still free from carbon filaments after $1752 \mathrm{~h}$ exposure. Carbon filament growth was more widespread on the NiCr-coated sample, with filaments being preferentially located along the sample edges.

XRD results for NiCr-coated Alloy 600 showed the presence of $\mathrm{Cr}_{23} \mathrm{C}_{6}$ and $\mathrm{Cr}_{2} \mathrm{O}_{3}$. XRD results from exposed NiCrAlY-coated Alloy 600 were the same as those from NiCrAlY-coated Alloy $800 \mathrm{H}$ : the bcc- $\alpha$ and fcc- $\gamma$ phases present in the as-sprayed coating were still present in addition to a $\beta(\mathrm{NiAl})$ phase which was not present prior to exposure; $\mathrm{Ni}_{3} \mathrm{Al}\left(\gamma^{\prime}\right)$, which was present in the as-sprayed coating, was again no longer detected after exposure; no oxides were detected. 


\section{Laser-treated NiCrAIY}

Laser-melted NiCrAlY coatings had a shiny, metallic appearance. A small amount of carbon deposition was apparent after short exposure times, $<100 \mathrm{~h}$. The deposited carbon was localised in discrete areas and did not lead to the notable blackening of the surface that was observed for non-laser-treated coated and uncoated samples. The metallic surface largely remained clearly visible and non-carbon blackened to the end of the tests: $385 \mathrm{~h}$ for Alloy $800 \mathrm{H}$ and $1726 \mathrm{~h}$ for Alloy 600 (Figure 11). After $1726 \mathrm{~h}$, there was sufficient carbon deposition on the NiCrAlY surface to show that the carbon was deposited in bands, corresponding to the laser tracks (c). SEM examination of this surface revealed that the adherent carbon deposits were preferentially located on the bands of oxide that bordered each laser track (Figure 12).

XRD results for the laser-treated NiCrAlY-coated Alloy 800H sample exposed for $385 \mathrm{~h}$ showed the presence of $\mathrm{AlNi}_{3}$ and several additional yttrium aluminium oxides, as well as the phases detected before exposure. The bcc structure seen in the as-deposited coating but not in the laser-treated coating was also detected. Similar XRD results were obtained for the laser-treated NiCrAlY-coated Alloy 600 sample, with the exception of $\mathrm{AlNi}_{3}$ which was not detected.

Localised carbon filaments were observed on the laser melted NiCrAlY on both alloys. Examination of the coated Alloy $800 \mathrm{H}$ sample that had significant, although localised, carbon filaments after $385 \mathrm{~h}$ (Figure 13), revealed that incomplete melting of the coating had occurred and the original as-sprayed interface was retained (Figure 14). Large, discrete, $\sim 25 \mu \mathrm{m}, \mathrm{Al}_{2} \mathrm{O}_{3}$ particles were observed at the interface. 


\section{Laser-treated $\mathrm{NiCr}$}

For both systems, the laser-melted $\mathrm{NiCr}$ surface became blackened by carbon deposition within $50 \mathrm{~h}$ (Figure 15a). Localised carbon filament growth was initiated on the coated Alloy $800 \mathrm{H}$ sample. By the end of the test, at $264 \mathrm{~h}$, extensive carbon filaments were observed (Figure 15b). However, these were not uniformly dispersed over the surface, being mainly restricted to the sample edges. Large regions of the sample surface were carbon blackened but free from carbon filaments. The coated Alloy 600 sample behaved similarly, although carbon filaments were only noted after $392 \mathrm{~h}$. Extensive filament growth was again largely restricted to the sample edges. Large areas of the sample surface were carbon blackened but remained without evidence of metal dusting to the end of the $1573 \mathrm{~h}$ exposure period (Figure 15d). For both systems, the deposited carbon did not form a complete layer, and non-blackened regions were always visible, making it possible to see the residual outlines of the laser tracks.

EDS revealed that the sample corners have slightly higher Fe contents, an average of $5.6 \pm 0.5$ at $\%$ compared to $4.7 \pm 0.2$ at $\%$ in the middle of the faces for laser melted NiCrAlY on Alloy 600. SEM examination of a cross-section of the exposed sample revealed that defects, such as incomplete melting and discrete very thick oxides, were restricted to the sample edges.

XRD results showed the presence of $\mathrm{Cr}_{23} \mathrm{C}_{6}$ and $\mathrm{Cr}_{2} \mathrm{O}_{3}$ for both systems. An unidentified spinel-type oxide was detected on the NiCr-coated Alloy 600 sample but not the NiCr-coated Alloy 800H sample. 


\section{Discussion}

\section{Coated samples}

As-deposited NiCrAlY coatings have performed well on both Alloy $800 \mathrm{H}$ and Alloy 600 . The coating itself was resistant to metal dusting. This was attributed to the formation of a protective alumina scale. Although $\mathrm{Al}_{2} \mathrm{O}_{3}$ was not detected by XRD, it is suggested that a thin $\mathrm{Al}_{2} \mathrm{O}_{3}$ layer was present but not in sufficient quantities to be distinguished from background noise in the XRD spectra. Following XRD results which indicated loss of $\beta(\mathrm{NiAl})$ and formation of $\gamma^{\prime}\left(\mathrm{Ni}_{3} \mathrm{Al}\right)$ on exposure, the observed outer coating degradation (Figure 5b) has been attributed to a $\beta-\gamma^{\prime}$ phase transition. However, localised metal dusting-induced coating failure was observed. This was due to carbon penetration through interconnected porosity in the coating (Figure 6b) to the underlying alloy which then underwent metal dusting. This led to both extensive localised carbon filament growth and coating spallation because the stresses generated by the volume of carbon filaments formed by metal dusting of the substrate led to mechanical failure of the coating (Figure 6a). The porosity present in as-deposited coatings has therefore been shown to impose limitations on, as well as introducing a large variability into, coating performance.

The NiCr coatings were not so successful. Coating spallation occurred from the Alloy $800 \mathrm{H}$ sample but not the Alloy 600 sample. The coating conditions were not optimised for the samples used in this work, resulting in an increased proportion of unmelted particles within the coating. This may have contributed to decreasing the adhesion of the coating, having a marked effect on the $\mathrm{NiCr}$ coating due to the additional effect of coefficient of thermal expansion (CTE) mis-matches. Stresses arising from CTE 
mis-matches between the coating and substrate could also have contributed to coating spallation. The CTE of the coating is not known. The CTE of the commercially available Ni46Cr Alloy 671 could not be used as an approximation since this consists of chromium carbides in a nickel matrix, very different from the two phase microstructure of the NiCr-coating used here. However, from literature CTE values for other $\mathrm{NiCr}$ alloys it is expected to be low $\left(\sim 12.5 \mu \mathrm{m} \mathrm{m}^{-1} \mathrm{~K}^{-1}\right.$ from the rule of mixtures) as $\mathrm{Cr}$ has a low CTE value (Table 4). Since Alloy $800 \mathrm{H}$ has a greater CTE than Alloy 600, CTE mis-match stresses would be greater in the NiCr-coated Alloy $800 \mathrm{H}$, which is consistent with the observed spallation. However, spallation did not occur when NiCr-coated Alloy $800 \mathrm{H}$ was exposed to temperature in flowing argon. This indicates that CTE mis-match stresses were not the sole reason for coating spallation and that exposure to the mixed gas environment also had some effect, although details of this interaction are not yet known.

For NiCr-coated Alloy 600, some improvement in metal dusting resistance was achieved; however this was limited by metal dusting degradation of the coating itself. XRD detected $\mathrm{Cr}_{2} \mathrm{O}_{3}$, although the presence of $\mathrm{Cr}_{2} \mathrm{O}_{3}$ did not prevent metal dusting. The $\mathrm{Cr}_{2} \mathrm{O}_{3}$ clearly did not form the desired continuous protective oxide layer. Carbon ingress was not prevented, as was proved by the formation of $\mathrm{Cr}_{23} \mathrm{C}_{6}$ as well as carbon filament growth.

The lattice parameter of the austenitic phase present in the as-deposited $\mathrm{NiCr}$ coating decreased as a result of exposure to the mixed gas atmosphere. Nickel has a smaller atomic radius than chromium. The decrease in the lattice parameter suggested a smaller chromium content in the austenitic phase. This was consistent with chromium depletion of the austenitic phase by formation of the chromia observed in the XRD spectrum 
(Figure 9). Preferential degradation of the Ni-rich phase then occurred because it contained insufficient chromium to form a protective oxide scale.

An initial step increase in mass was seen for each coated system, with the exception of NiCr-coated Alloy $800 \mathrm{H}$ which failed too early for such an effect to be resolved. This initial increase was partly attributed to carbon deposition on the sample surface; this was larger than for the non-coated samples since the former have larger specific surface areas due to the roughness of the surface and to surface-connected porosity. However, the expected difference in specific surface areas was not large enough to explain the magnitude of the initial step-increase in mass. It was possible that local changes in conditions, such as different carbon and oxygen activities generated within surface pores, also contributed to the observed initial mass increase. Since this effect would stop once pores were filled with carbon, the step-like nature of the increase would be explained. It should be noted that, while the coated samples gave larger total mass gains, the rates of mass gain were actually less than those of the non-coated samples during exposure from $\sim 200$ h onwards.

The XRD results were the same for both NiCrAlY coated systems. This, together with the fact that the average rates of mass gain were approximately the same, indicated that the substrate did not come into contact with the environment, confirming that the coating formed an effective barrier for these exposure times (Table 3). The significantly higher rate of mass gain for NiCr-coated Alloy 600 is due to metal dusting degradation of the coating. Due to the early failure of the NiCr-coated Alloy $800 \mathrm{H}$ sample, no meaningful rate of mass gain could be calculated. 
Overall, the alumina-forming $\mathrm{NiCrAlY}$ coating outperformed the chromia-forming $\mathrm{NiCr}$ coating despite the fact that chromia-forming materials are generally more metal dusting resistant due to the faster growth kinetics of chromia compared to alumina. Detectable quantities of chromia were formed during exposure. However, a continuous protective chromia scale was not formed due to the two-phase microstructure of the coating: the Cr-rich phase was protected, the Ni-rich phase underwent metal dusting which led to disintegration of the coating. The superior performance of the NiCrAlY coating is attributed to formation of a continuous protective alumina scale.

\section{Laser treated coatings}

Laser-treated NiCrAlY coatings performed well, producing a marked decrease in the extent of carbon deposition on both alloys. This effect was apparent from the appearance of the samples, although not from the mass difference results as the laser-treated samples failed in discrete areas where extensive metal dusting occurred and, hence, contributed to the mass difference results.

Examination in cross-section revealed that the extensive carbon filament growth seen after $385 \mathrm{~h}$ on the Alloy $800 \mathrm{H}$ sample was restricted to a region in which incomplete melting of the original coating had occurred. Large, $\sim 25 \mu \mathrm{m}$, particles of $\mathrm{Al}_{2} \mathrm{O}_{3}$ were seen at the coating/substrate interface. These particles did not form during laser-treatment or exposure since they were also observed in as-received coated samples. They had been embedded in the substrate surface during shot blasting prior to coating. On laser treatment, the presence of such $\mathrm{Al}_{2} \mathrm{O}_{3}$ at the coating/substrate interface may have acted as a thermal resistance, inhibiting interfacial melting. However, while incomplete melting makes coating spallation more likely, it does not explain why it occurs. Figure 14 shows 
large pores in the laser-melted coating, these are attributed to agglomeration of the pre-existing coating porosity during laser-treatment [41]. In order to induce directly metal dusting, such pores would have had either to have been surface connected to permit carbon ingress, or to have acted as stress concentrators during thermal loading [41], leading to surface connected cracks. However, no evidence confirming either of these scenarios was found.

The limited carbon deposition that did occur on the laser-treated NiCrAlY coatings showed a preference for the laser-induced-oxide bands on the sample surface (Figure 12). XRD results revealed the presence of spinel oxides within the laser-induced oxide. The preferential location of the carbon deposits on the oxide was attributed to Fe-spinel oxides. Such oxides may have been reduced in the metal dusting environment and then subsequently catalysed carbon deposition. Laser-induced oxides on uncoated Alloy $800 \mathrm{H}$ have previously been linked to a possible decrease in metal dusting resistance [42]. Though limited in extent here, this form of carbon deposition may be of concern for longer term exposure of laser-treated NiCrAlY. However, the necessary elimination of laser-induced oxides by improved sample shielding should be simple.

The laser-treated NiCr-coated samples also largely performed well but underwent extensive metal dusting in localized regions. The sample edges proved to be preferential sites for carbon filament growth. This was particularly the case for the coated Alloy 600 system and may again be attributed to the presence and subsequent reduction of $\mathrm{Fe}$ containing spinel oxides. These oxides were more likely to have formed at the edges of the sample, where deeper melt depths and, hence, increased Fe contents were observed. This increased coating dilution at the sample edges is a direct result of the small samples 
used in this work. Such effects would be minimised in industrial application where the significantly larger surfaces processed would ensure a uniform thermal history for each part of the surface. Due to the influence of edge effects on the results in this paper (producing some extensive localized carbon deposition), the images of the exposed samples must be taken into account when considering the mass difference data.

The overall improvement in metal dusting resistance of the laser-treated coatings compared with the as-deposited coatings was attributed to the elimination of interconnected porosity during laser treatment. This eliminated easy access paths for carbon ingress, as confirmed by EPMA mapping (Figure 16) which revealed carbon ingress in as-deposited coatings but did not detect any carbon ingress in laser-treated coatings.

It is acknowledged that the vacuum plasma sprayed coatings used in this work were not optimised and hence contain a greater quantity of unmelted particles, and hence, inter-connected porosity than would generally be expected. All plasma sprayed coatings contain inter-connected porosity and could therefore benefit from the laser treatment described in this work. As the improvement in metal dusting resistance is expected to increase with the original extent of inter-connected porosity, the benefits to optimised coatings may be less than reported here.

\section{Conclusions}

1. Thermally sprayed coatings have been shown to improve the metal dusting resistance of Alloy $800 \mathrm{H}$ and Alloy 600. The coatings act as a physical barrier to 
carbon ingress, although the effectiveness of the coatings can be limited by the presence of interconnected porosity typical of thermally sprayed coatings.

2. Ni31Cr11Al0.6Y proved to be a suitable coating for both alloys. A Ni50Cr coating was less successful, being observed to undergo metal dusting as well as spalling from Alloy $800 \mathrm{H}$. The spallation is attributed to the non-optimal as-sprayed coating and CTE mis-matches which may have also enhanced metal dusting of the coating prior to spallation.

3. Laser-melting has further improved the metal dusting resistance of the thermally sprayed coated samples. This is due to improving the effectiveness of the coating as a barrier to carbon ingress by elimination of interconnected porosity.

4. The performance of the laser-melted coatings has been limited by defects in the system. However, these are largely due to specimen edge effects and the main surfaces exhibited good resistance to the environment.

\section{Acknowledgements}

The authors are grateful for a research grant from the Engineering and Physical Sciences Research Council (GR/R17669) to support this research. 


\section{References}

1. M. L. Holland. Practical Experience with Countering Metal Dusting in a Methane Reforming Unit, in Proceedings of Corrosion 2001, Paper 01385, National Association of Corrosion Engineers, Houston, Texas, USA.

2. R. F. Hochman. Basic Studies of Metal Deterioration ("Metal Dusting") in Carbonaceous Environments at Elevated Temperatures, in Proceedings of the 5th Metallic Corrosion Conference,1972, National Association of Corrosion Engineers, Houston, Texas, USA.

3. R. F. Hochman, Catastrophic Deterioration of High Temperature Alloys in Carbonaceous Atmospheres, Proceedings of the Electrochemical Society, 1976. 77: p. 715-732.

4. R. F. Hochman. Metal Deterioration in Carbon Monoxide and Hydrocarbon at Elevated Temperatures, in Proceedings of the 3rd International Congress on Metallic Corrosion, 1966, Moscow, USSR: Moscow Press (1969).

5. H. J. Grabke and M. Spiegel, Occurrence of Metal Dusting - Referring to Failure Cases, Materials \& Corrosion, 2003, 54: p. 799-804.

6. H. J. Grabke, Corrosion by Carbonaceous Gases, Carburization and Metal Dusting, and Methods of Prevention, Materials at High Temperatures, 2000, 17: p. 483487.

7. H. J. Grabke, Thermodynamics, Mechanisms and Kinetics of Metal Dusting. Materials and Corrosion, 1998, 49: p. 303-308.

8. R. Schneider, E. Pippel, J. Woltersdorf, S. Strauss and H. J. Grabke, Microprocesses of Metal Dusting on Nickel and Ni-base Alloys, Steel Research, 1997. 68: p. 326-332.

9. P. Szakálos, Mechanisms and Driving Forces of Metal Dusting. Materials and Corrosion, 2003, 54: p. 752-762.

10. P. Szakálos, R. Pettersson and S. Hertzman, An Active Corrosion Mechansim for Metal Dusting on 304L Stainless Steel, Corrosion Science, 2002, 44: p. 2253-2270. 
11. P. Szakálos and L. Liu. Mechanisms of Metal Dusting - Application to Alloy Composition, Temperature and Pressure, in Proceedings of the15th International Corrosion Congress "Frontiers in Corrosion Science and Technology", 2002, Granada, Spain.

12. H. J. Grabke, Metal Dusting, Materials \& Corrosion, 2003, 54: p. 736-746.

13. R. T. Jones and K. L. Baumert. Metal Dusting - an Overview of Current Literature, in Proceedings of Corrosion 2001, Paper 01372, National Association of Corrosion Engineers, Houston, Texas, USA.

14. R. Kirchheiner and J. L. J. Soler. Correlation of Oxidation, Carburization and Metal Dusting; "Controlling Corrosion by Corrosion", in Proceedings of Corrosion 2001, Paper 01374, National Association of Corrosion Engineers, Houston, Texas, USA.

15. E. Pippel, J. Woltersdorf and R. Schneider, Micromechanisms of Metal Dusting on Fe-Base and Ni-Base Alloys, Materials and Corrosion, 1998, 49: p. 309-316.

16. H. J. Grabke, E. M. Müller-Lorenz, S. Strauss, E. Pippel and J. Woltersdorf, Effects of Grain Size, Cold Working, and Surface Finish on the Metal-Dusting Resistance of Steels, Oxidation of Metals, 1998, 50: p. 241-254.

17. I. Wolf and H. J. Grabke, A Study on the Solubility and Distribution of Carbon in Oxides, Solid State Communications, 1985, 54: p. 5-10.

18. G. T. Bayer. Surface Engineering Coatings for Metal Dusting, in Proceedings of Corrosion 2001, Paper 01387, National Association of Corrosion Engineers, Houston, Texas, USA.

19. E. J. Hapnes, 1999, Effect of Different Pretreatments of Metallic Compounds on Corrosion Resistance on Metal Dusting, Thesis, Norwegian University of Science and Technology: Trondheim.

20. R. J. Gommans and T. L. Huurdeman. DSM's Experience with Metal Dusting in Waste Heat Boilers. in AlChE Ammonia Safety Symposium, 1994, Vancouver, Canada. 
21. K. L. Baumert and J. J. Hoffmann. Materials Experience in Methanol Reforming Units, in Proceedings of Corrosion'97, 1997, National Association of Corrosion Engineers, Houston, Texas, USA.

22. W. Zychlinski, K. A. Wynns and B. Ganser, Charaterization of Material Samples for Coking Behaviour of HP40 Material both Coated and Uncoated using Naphtha and Ethane Feedstock, Materials and Corrosion, 2002, 53: p. 30-36.

23. A. Kurlekar and G. T. Bayer, Enhance Furnace Tube Resistance to Carburization and Coke Formation, Hydrocarbon Processing, 2001, 80: p. 80-84.

24. C. Rosado, F. Dettenwanger and M. Schütze. Protection of Steels Against Metal Dusting Attack by Coatings, in Proceedings of Eurocorr 2001, Lake Garda, Italy.

25. C. Rosado and M. Schütze, Protective Behaviour of Newly Developed Coatings Against Metal Dusting, Materials and Corrosion, 2003, 54: p. 831-853.

26. Y. Wang and W. Chen, Microstructures, Properties and High-Temperature Carburization Resistances of HVOF Thermal Sprayed NiAl Intermetallic-Based Alloy Coatings, Surface and Coatings Technology, 2004, 183: p. 18-28.

27. S. Nuutinen, P. Vuoristo, S. Ahmaniemi, T. Mäntylä and J. Takeuchi. A Microstructural Study of HVOF and VPS Sprayed MCrAlY Coatings, in Proceedings of Thermal Spray 2001, Singapore: ASM Int.

28. M. L. Capp and J. M. Rigsbee, Laser Processing of Plasma-Sprayed Coatings. Materials Science and Engineering, 1984, 62: p. 49-56.

29. T. Weber, C. Rosado and M. Schütze. Development of Coatings for Environments with High Sulfur and/or Carbon Activities at Low Oxygen Potentials, in Proceedings of Corrosion 2002, Paper 02376, National Association of Corrosion Engineers, Houston, Texas, USA.

30. B. S. Sidhu, D. Puri and S. Prakash, Characterisations of Plasma Sprayed and Laser Remelted NiCrAlY Bond Coats and $\mathrm{Ni}_{3} \mathrm{Al}$ Coatings on Boiler Tube Steels, Materials Science and Engineering A, 2004. 368: p. 149-158. 
31. J. Tuominen, P. Vuoristo, T. Mäntylä, S. Ahmaniemi, J. Vihinen and P. H. Andersson, Corrosion Behaviour of HVOF-Sprayed and Nd:YAG Laser-Remelted HighChromium, Nickel-Chromium Coatings, Journal of Thermal Spray Technology, 2002, 11: p. 233-243.

32. A. Pokhmurska and R. Ciach, Microstructure and Properties of Laser Treated Arc Sprayed and Plasma Sprayed Coatings, Surface and Coatings Technology, 2000, 125: p. 415-418.

33. Y. N. Wu, G. Zhang, Z. C. Feng, B. C. Zhang, Y. Liang and F. J. Liu, Oxidation Behaviour of Laser Remelted Plasma Sprayed NiCrAlY and NiCrAlY- $\mathrm{Al}_{2} \mathrm{O}_{3}$ Coatings, Surface and Coatings Technology, 2001, 138: p. 56-60.

34. E. Fernández, J. R. Garcia, J. M. Cuetos and V. Higuera, Behaviour of Laser Treated Cr, Ni Coatings in the Oxidative Atmosphere of a Steam Boiler, Surface and Coatings Technology, 2005, 195: p. 1-7.

35. T. W. Clyne, Residual Stresses in Thick and Thin Surface Coatings, in Encyclopaedia of Materials: Science and Technology, A. Mortensen, Editor, 2001, Elsevier. p. 4.1.3b.

36. D. Z. Guo, F. L. Li, J. Y. Wang and J. S. Sun, Effects of Post-Coating Processing on Structure and Erosive Wear Characteristics of Flame and Plasma Spray Coatings, Surface and Coatings Technology, 1995, 73: p. 73-78.

37. Y. P. Zhang, Z. R. Zhou, J. M. Cheng, Y. L. Ge and H. Ma, Laser Remelting of NiCoCrAlY Clad Coating on Superalloy, Surface and Coatings Technology, 1996. 79: p. 131-134.

38. M. C. Flemings, Solidification Processing, 1974: McGraw-Hill Inc.

39. W. Kurz and D. J. Fisher, Fundamentals of Solidification, 1992, Switzerland: Trans Tech Publications.

40. Smithells Metals Reference Book. 6th ed., 1983: Butterworths. 
41. D. Triantafyllidis, L. Li and F. H. Stott, Mechanisms of Porostiy Formation Along the Solid/Liquid Interface During Laser Melting of Ceramics, Applied Surface Science, 2003, 208-9: p. 458-462.

42. K. T. Voisey, Z. Liu and F. H. Stott, Inhibition of Metal Dusting of Alloy $800 \mathrm{H}$ by Laser Surface Melting, Applied Surface Science, in press, accepted May 2005.

43. A. S. Pavlovic, V. S. Babu and M. S. Seehra, High-Temperature Thermal Expansion of Binary Alloys of Ni with Cr, Mo and Re: A Comparison with Molecular Dynamics Simulation, J. Phys: Condensed Matter, 1996, 8: p. 3139-3149.

44. Smithells Metals Reference Book. 8th ed., 2004, Amsterdam: Elsevier Butterworth-Heinemann. 


\section{Tables}

\begin{tabular}{|c|c|c|c|c|c|c|c|c|c|c|c|c|c|c|}
\hline & $\mathrm{Al}$ & $\mathrm{C}$ & $\mathrm{Co}$ & $\mathrm{Cr}$ & $\mathrm{Cu}$ & $\mathrm{Fe}$ & $\mathrm{Mn}$ & $\mathrm{Mo}$ & $\mathrm{Nb}$ & $\mathrm{Ni}$ & $\mathrm{S}$ & $\mathrm{Si}$ & $\mathrm{Ti}$ & $\mathrm{P}$ \\
\hline $\begin{array}{c}\text { Alloy } \\
600\end{array}$ & 0.29 & 0.04 & & 16.42 & & 9.5 & 0.38 & 0.23 & 0.2 & 72.43 & & 0.26 & 0.25 & \\
\hline $\begin{array}{c}\text { Alloy } \\
800 \mathrm{H}\end{array}$ & 0.22 & 0.067 & 0.06 & 19.67 & 0.16 & 45.34 & 0.76 & 0.29 & 0.02 & 33.05 & $<0.001$ & 0.08 & 0.27 & 0.012 \\
\hline
\end{tabular}

Table 1 Compositions (wt\%) of the alloys, as supplied by the manufacturers for the specific batches of material.

\begin{tabular}{|c|c|c|c|}
\hline Substrate & Coating & $\begin{array}{c}\text { Power } \\
(\mathrm{W})\end{array}$ & $\begin{array}{c}\text { Velocity } \\
\left(\mathrm{mm} \mathrm{s}^{-1}\right)\end{array}$ \\
\hline Alloy $800 \mathrm{H}$ & $\mathrm{NiCrAlY}$ & 1500 & 100 \\
\hline Alloy $800 \mathrm{H}$ & $\mathrm{NiCr}$ & 1200 & 75 \\
\hline Alloy 600 & $\mathrm{NiCrAlY}$ & 1400 & 100 \\
\hline Alloy 600 & $\mathrm{NiCr}$ & 650 & 75 \\
\hline
\end{tabular}

Table 2 Laser processing parameters.

\begin{tabular}{|c|c|}
\hline Sample & $\begin{array}{c}\text { Rate of mass gain } \\
\left(\mathrm{mg} \mathrm{mm}^{-2} \mathrm{~h}^{-1}\right)\end{array}$ \\
\hline Alloy $800 \mathrm{H}+\mathrm{NiCrAlY}$ & 23 \\
\hline Alloy $600+\mathrm{NiCrAlY}$ & 25 \\
\hline Alloy $600+\mathrm{NiCr}$ & 61 \\
\hline
\end{tabular}

Table 3 Rates of mass gain for coated samples, Alloy $800 \mathrm{H}+\mathrm{NiCr}$ is not included due to the early failure of the sample. 


\begin{tabular}{|c|c|}
\hline Material & $\begin{array}{c}\text { Coefficient of Thermal } \\
\text { Expansion } \\
\mu \mathrm{m} \mathrm{m}^{-1} \mathrm{~K}^{-1}\end{array}$ \\
\hline $\mathrm{Ni}$ & $19^{1}$ \\
& $15.8^{2}$ \\
\hline $\mathrm{Ni8Cr}$ & $18^{1}$ \\
\hline $\mathrm{Ni} 6 \mathrm{Cr}$ & $18^{1}$ \\
\hline $\mathrm{Cr}$ & $9.4^{2}$ \\
\hline Alloy 600 & $15.8^{3}$ \\
\hline Alloy $800 \mathrm{H}$ & $17.5^{3}$ \\
\hline
\end{tabular}

Table 4 Coefficient of thermal expansion data for $\mathrm{NiCr}$ alloys. 1: extrapolated value for $700^{\circ} \mathrm{C}$ [43] 2: average value for $20^{\circ} \mathrm{C}-700^{\circ} \mathrm{C}$ [44] 3: manufacturer's value. 


\section{Figure Captions}

Figure $1 \mathrm{XRD}$ spectra for as-sprayed and laser treated NiCrAlY coated samples. Peaks corresponding to $\mathrm{Al}_{2} \mathrm{O}_{3}$ are labelled $\mathrm{A}$.

Figure 2 XRD spectra for as-sprayed and laser-treated $\mathrm{NiCr}$ coated samples. All unlabelled peaks are attributed to $\mathrm{Cr}_{2} \mathrm{O}_{3}$.

Figure 3 Mass difference results for Alloy $800 \mathrm{H}$ samples after exposure to the $20 \mathrm{H}_{2} / 80 \mathrm{CO}$ environment at $650^{\circ} \mathrm{C}$.

Figure 4 Optical micrographs in plan of uncoated Alloy $800 \mathrm{H}$ after exposure to the $20 \mathrm{H}_{2} / 80 \mathrm{CO}$ environment at $650^{\circ} \mathrm{C}$ (a) for $96 \mathrm{~h}$ (b) for $221 \mathrm{~h}$.

Figure $5 \mathrm{NiCrAlY}$-coated samples after exposure to the $20 \mathrm{H}_{2} / 80 \mathrm{CO}$ environment at $650^{\circ} \mathrm{C}$. (a) NiCrAlY-coated Alloy $800 \mathrm{H}$ after $992 \mathrm{~h}$ exposure (b) NiCrAlY-coated Alloy 600 after $900 \mathrm{~h}$ exposure.

Figure $6 \mathrm{NiCrAlY}$-coated Alloy $800 \mathrm{H}$ after exposure to the $20 \mathrm{H}_{2} / 80 \mathrm{CO}$ environment at $650^{\circ} \mathrm{C}$. (a) Optical micrograph taken after $607 \mathrm{~h}$ exposure, (b) EPMA carbon map of carbon ingress after $310 \mathrm{~h}$, exposure, brighter regions correspond to higher carbon concentrations, (c) back scattered SEM micrograph of area featured in EPMA map.

Figure $7 \mathrm{NiCr}$-coated Alloy $800 \mathrm{H}$ after $50 \mathrm{~h}$ exposure to the $20 \mathrm{H}_{2} / 80 \mathrm{CO}$ environment at $650^{\circ} \mathrm{C}$. (a) Low magnification optical image showing coating spallation, (b) SEM micrograph at $100 \mathrm{~h}$ showing metal dusting degradation of $\mathrm{NiCr}$ coating.

Figure 8 EPMA elemental maps and corresponding back scattered SEM micrograph for $\mathrm{NiCr}$-coated Alloy $800 \mathrm{H}$ after $100 \mathrm{~h}$ exposure to the $20 \mathrm{H}_{2} / 80 \mathrm{CO}$ environment at $650^{\circ} \mathrm{C}$.

Figure 9 XRD spectra for as-sprayed and exposed NiCr coated samples. Chromia, and graphite peaks are labelled $\mathrm{C}$ and $\mathrm{G}$ respectively. The original positions of the austenite peaks are labelled $\mathrm{A}_{\text {orig, }}$, the shifted positions after exposure are labelled $\mathrm{A}$.

Figure 10 Mass difference results for Alloy 600 (a) up to $2000 \mathrm{~h}$ (b) up to $1000 \mathrm{~h}$.

Figure 11 Optical micrographs of laser melted NiCrAlY after exposure to the $20 \mathrm{H}_{2} / 80 \mathrm{CO}$ environment at $650^{\circ} \mathrm{C}$ (a) laser melted NiCrAlY-coated Alloy $800 \mathrm{H} 385 \mathrm{~h} \mathrm{(b} \mathrm{\&} \mathrm{c)} \mathrm{laser}$ melted NiCrAlY-coated Alloy $6001726 \mathrm{~h}$.

Figure 12 SEM micrograph showing preferential location of carbon deposits on oxide (dark) regions on laser melted NiCrAlY on Alloy 600, $1726 \mathrm{~h}$. Carbon deposits on the left half of the image have been circled in white.

Figure 13 Extensive localised carbon filament growth on laser melted NiCrAlY coated Alloy $800 \mathrm{H} 385 \mathrm{~h}$.

Figure 14 Laser melted NiCrAlY coated Alloy $800 \mathrm{H} 385$ h. Embedded $\mathrm{Al}_{2} \mathrm{O}_{3}$ at the interface has resulted in incomplete melting, large pores are present in the laser melted layer.

Figure 15 Laser-treated $\mathrm{NiCr}$ after exposure to the $20 \mathrm{H}_{2} / 80 \mathrm{CO}$ environment at $650^{\circ} \mathrm{C}$. (a) Laser-treated NiCr-coated Alloy 80047 h (b) 264 h (c) Laser-treated NiCr-coated Alloy $60047 \mathrm{~h}(\mathrm{~d}) 1573 \mathrm{~h}$. 
Figure 16 EPMA carbon map and corresponding back scattered SEM micrograph for laser-treated $\mathrm{NiCrAlY}$-coated Alloy $800 \mathrm{H}$ after $310 \mathrm{~h}$ exposure to the $20 \mathrm{H}_{2} / 80 \mathrm{CO}$ environment at $650^{\circ} \mathrm{C}$. 
Figures

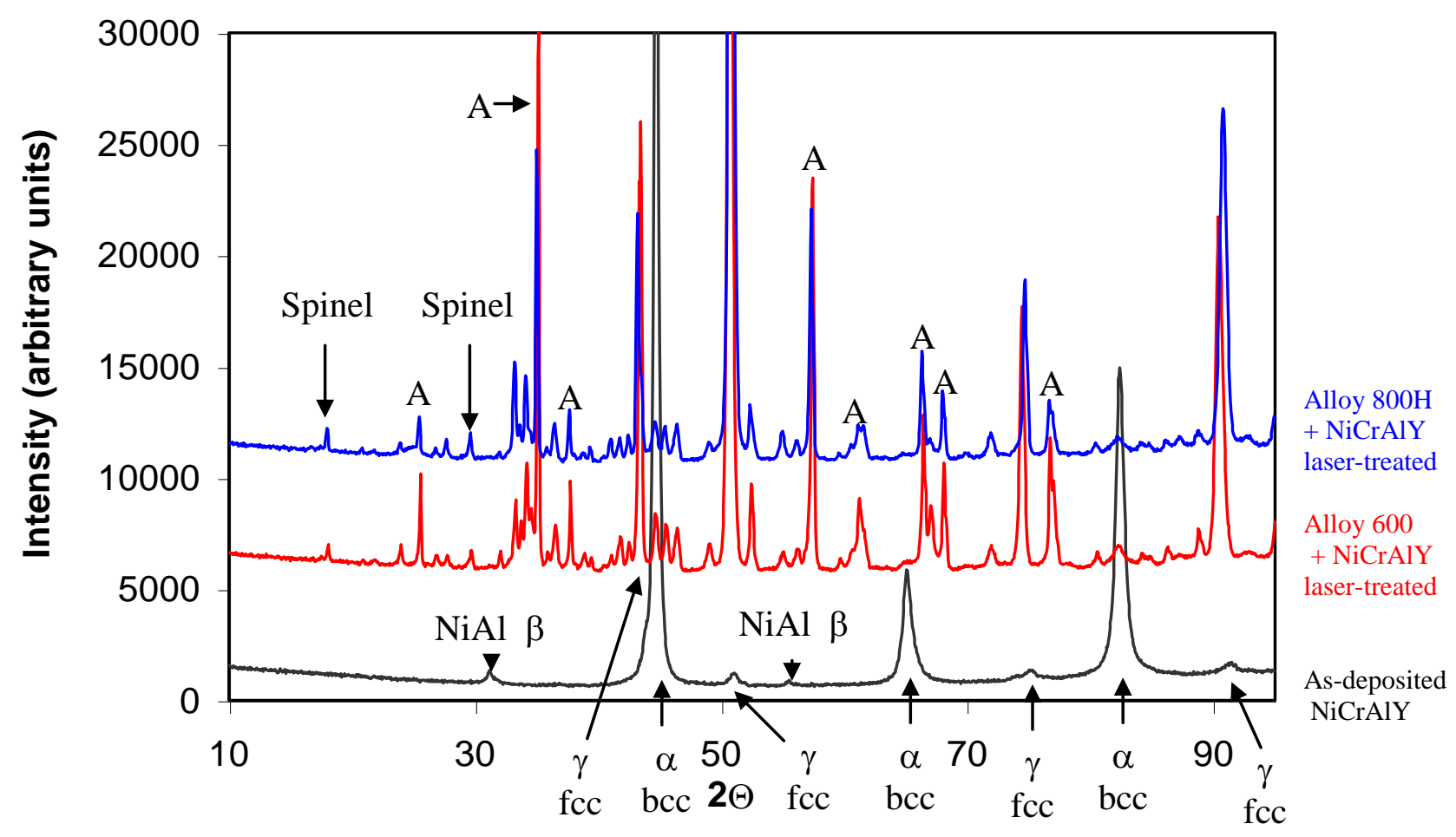

Figure $1 \mathrm{XRD}$ spectra for as-sprayed and laser treated NiCrAlY coated samples. Peaks corresponding to $\mathrm{Al}_{2} \mathrm{O}_{3}$ are labelled $\mathrm{A}$. 


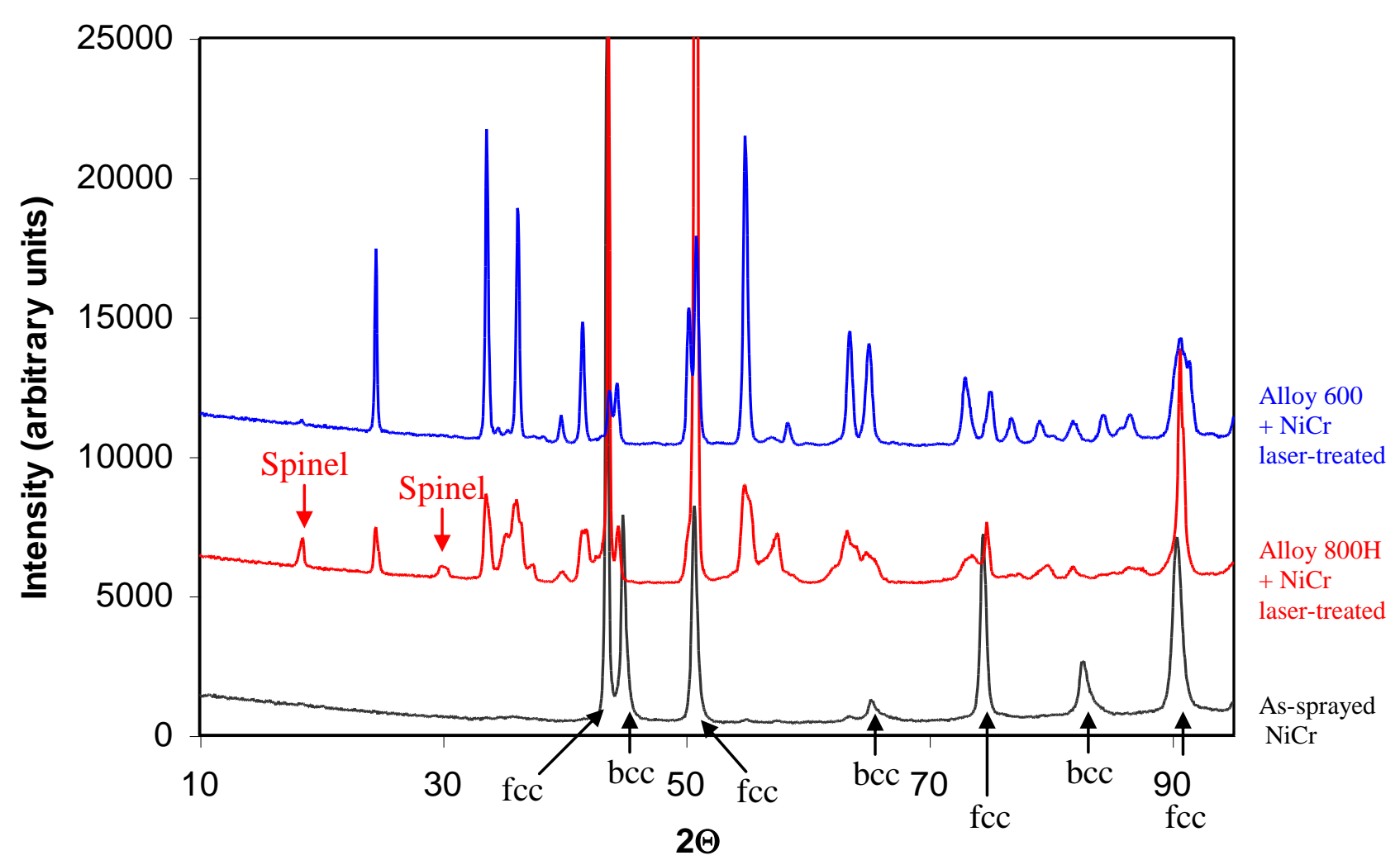

Figure $2 \mathrm{XRD}$ spectra for as-sprayed and laser-treated $\mathrm{NiCr}$ coated samples. All unlabelled peaks are attributed to $\mathrm{Cr}_{2} \mathrm{O}_{3}$.

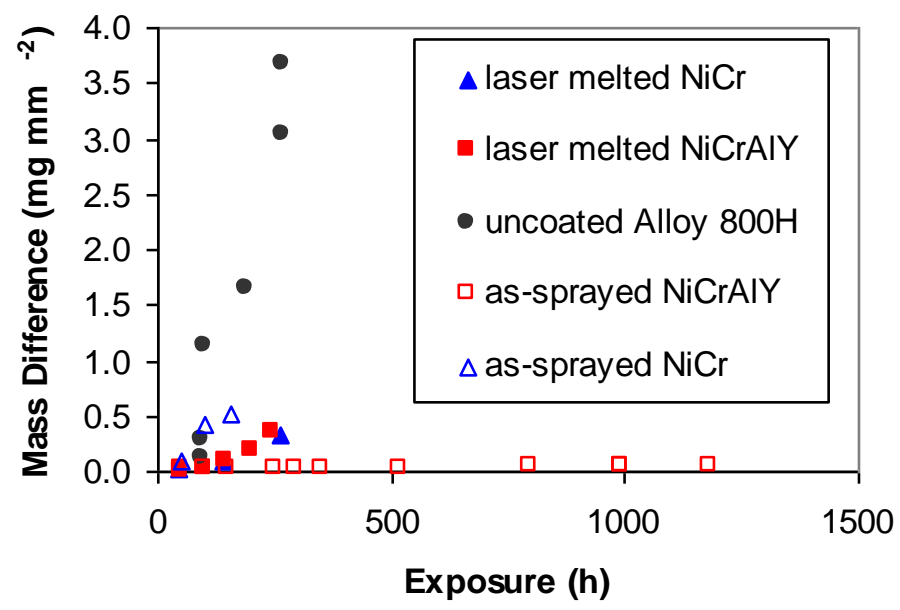

Figure 3 Mass difference results for Alloy $800 \mathrm{H}$ samples after exposure to the $20 \mathrm{H}_{2} / 80 \mathrm{CO}$ environment at $650^{\circ} \mathrm{C}$. 


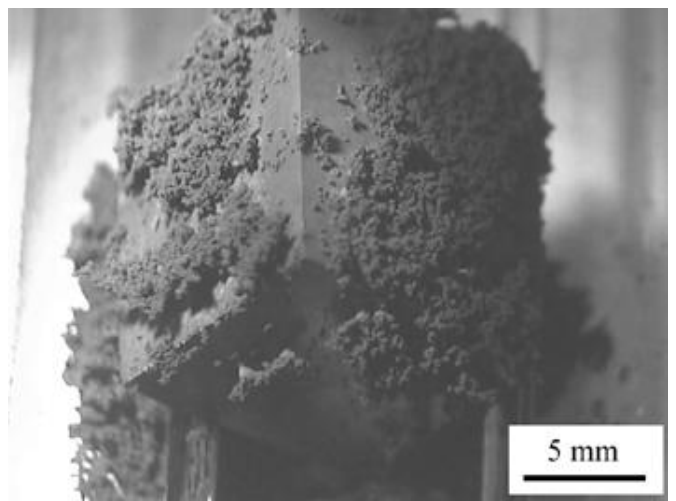

(a)

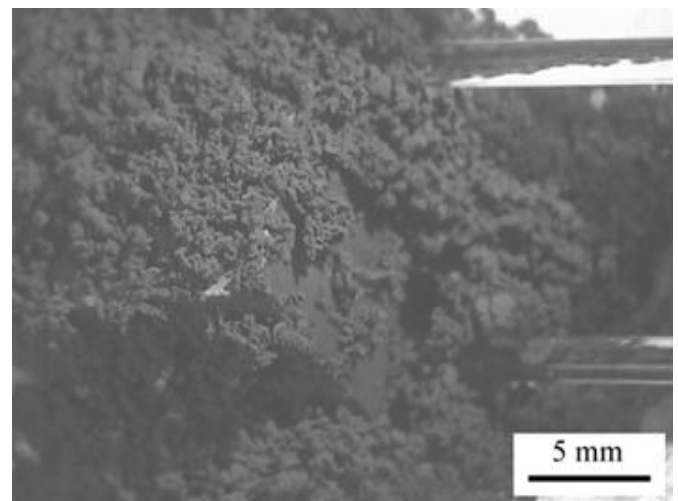

(b)

Figure 4 Optical micrographs in plan of uncoated Alloy $800 \mathrm{H}$ after exposure to the $20 \mathrm{H}_{2} / 80 \mathrm{CO}$ environment at $650^{\circ} \mathrm{C}$ (a) for $96 \mathrm{~h}$ (b) for $221 \mathrm{~h}$.

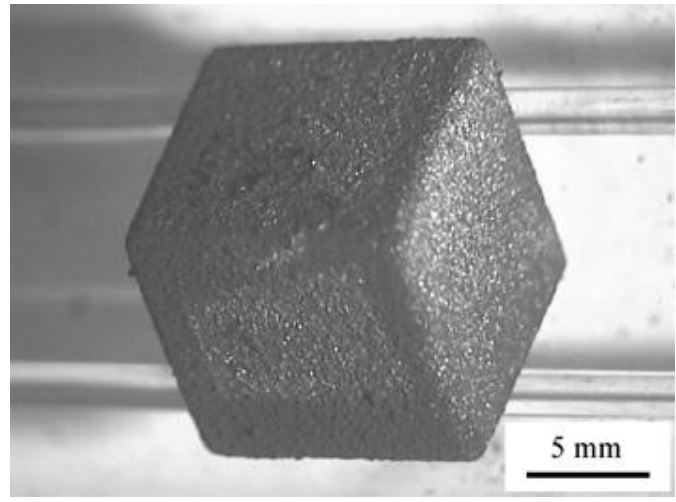

(a)

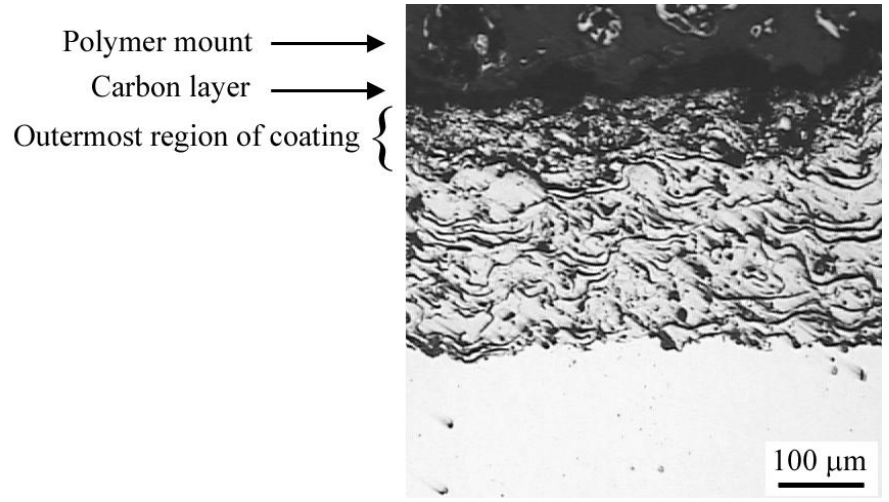

(b)

Figure $5 \mathrm{NiCrAlY}$-coated samples after exposure to the $20 \mathrm{H}_{2} / 80 \mathrm{CO}$ environment at $650^{\circ} \mathrm{C}$. (a) NiCrAlY-coated Alloy $800 \mathrm{H}$ after $992 \mathrm{~h}$ exposure (b) NiCrAlY-coated Alloy 600 after $900 \mathrm{~h}$ exposure.

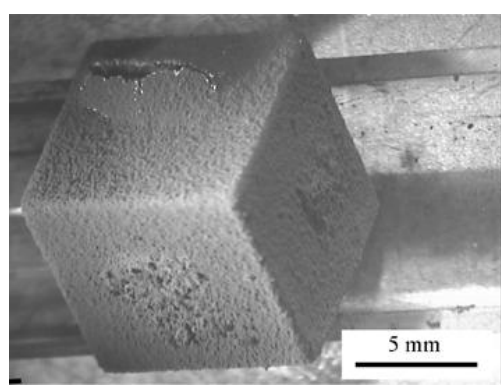

(a)

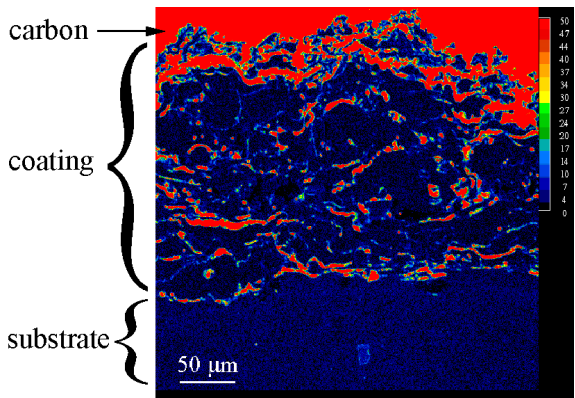

(b)

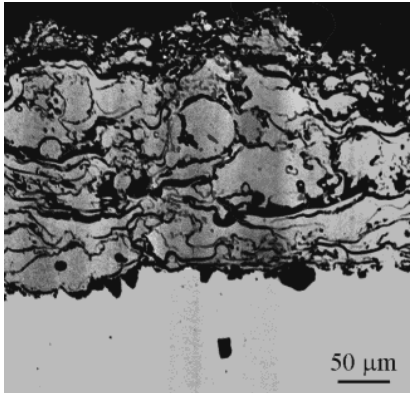

(c)

Figure $6 \mathrm{NiCrAlY}$-coated Alloy $800 \mathrm{H}$ after exposure to the $20 \mathrm{H}_{2} / 80 \mathrm{CO}$ environment at $650^{\circ} \mathrm{C}$.

(a) Optical micrograph taken after $607 \mathrm{~h}$ exposure, (b) EPMA carbon map of carbon ingress after $310 \mathrm{~h}$, exposure, brighter regions correspond to higher carbon concentrations, (c) back scattered SEM micrograph of area featured in EPMA map. 


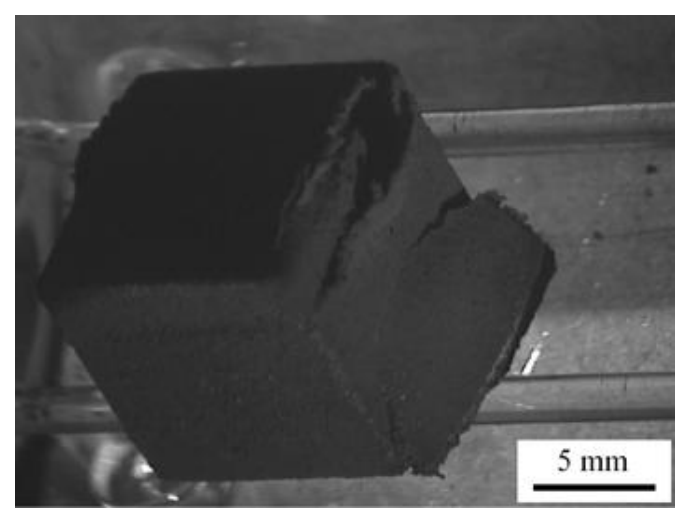

(a)

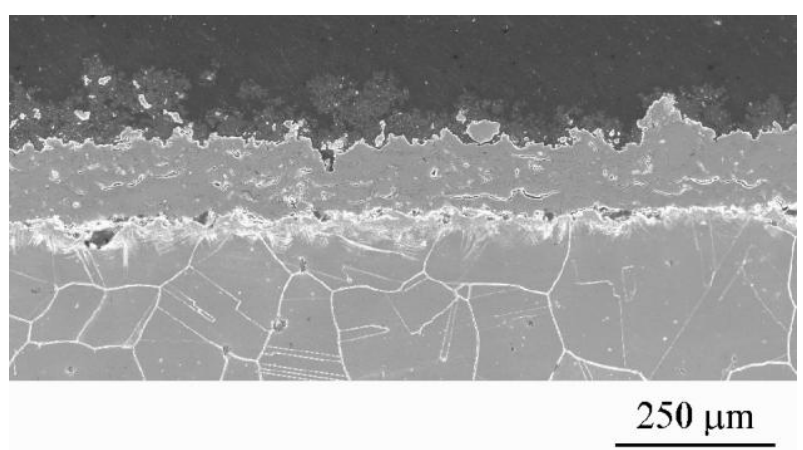

(b)

Figure $7 \mathrm{NiCr}$-coated Alloy $800 \mathrm{H}$ after $50 \mathrm{~h}$ exposure to the $20 \mathrm{H}_{2} / 80 \mathrm{CO}$ environment at $650^{\circ} \mathrm{C}$. (a) Low magnification optical image showing coating spallation, (b) SEM micrograph at $100 \mathrm{~h}$ showing metal dusting degradation of $\mathrm{NiCr}$ coating.

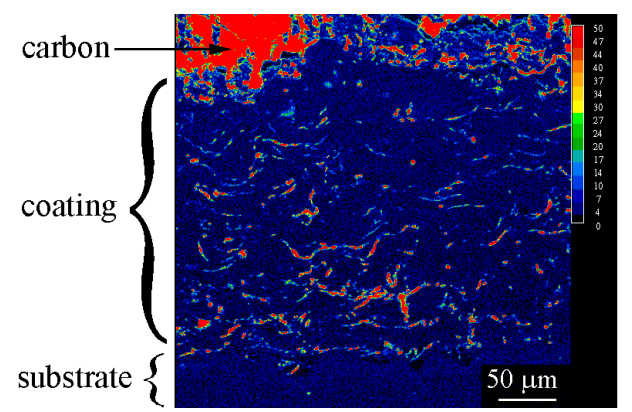

$\mathrm{C}$

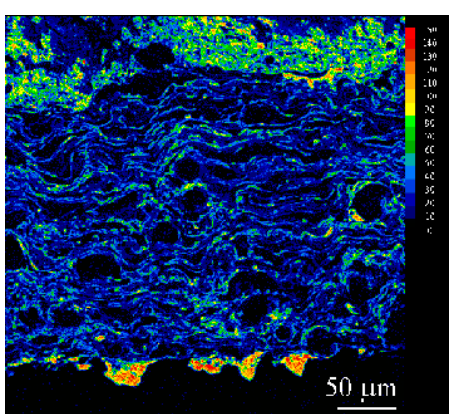

$\mathrm{O}$

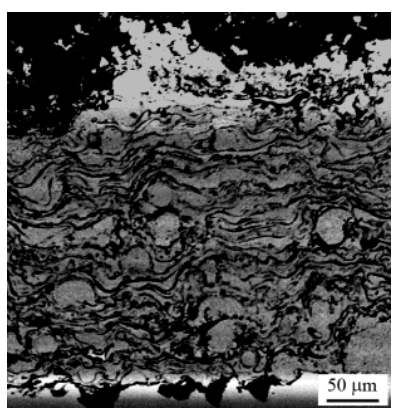

SEM

Figure 8 EPMA elemental maps and corresponding back scattered SEM micrograph for NiCr-coated Alloy $800 \mathrm{H}$ after $100 \mathrm{~h}$ exposure to the $20 \mathrm{H}_{2} / 80 \mathrm{CO}$ environment at $650^{\circ} \mathrm{C}$. 


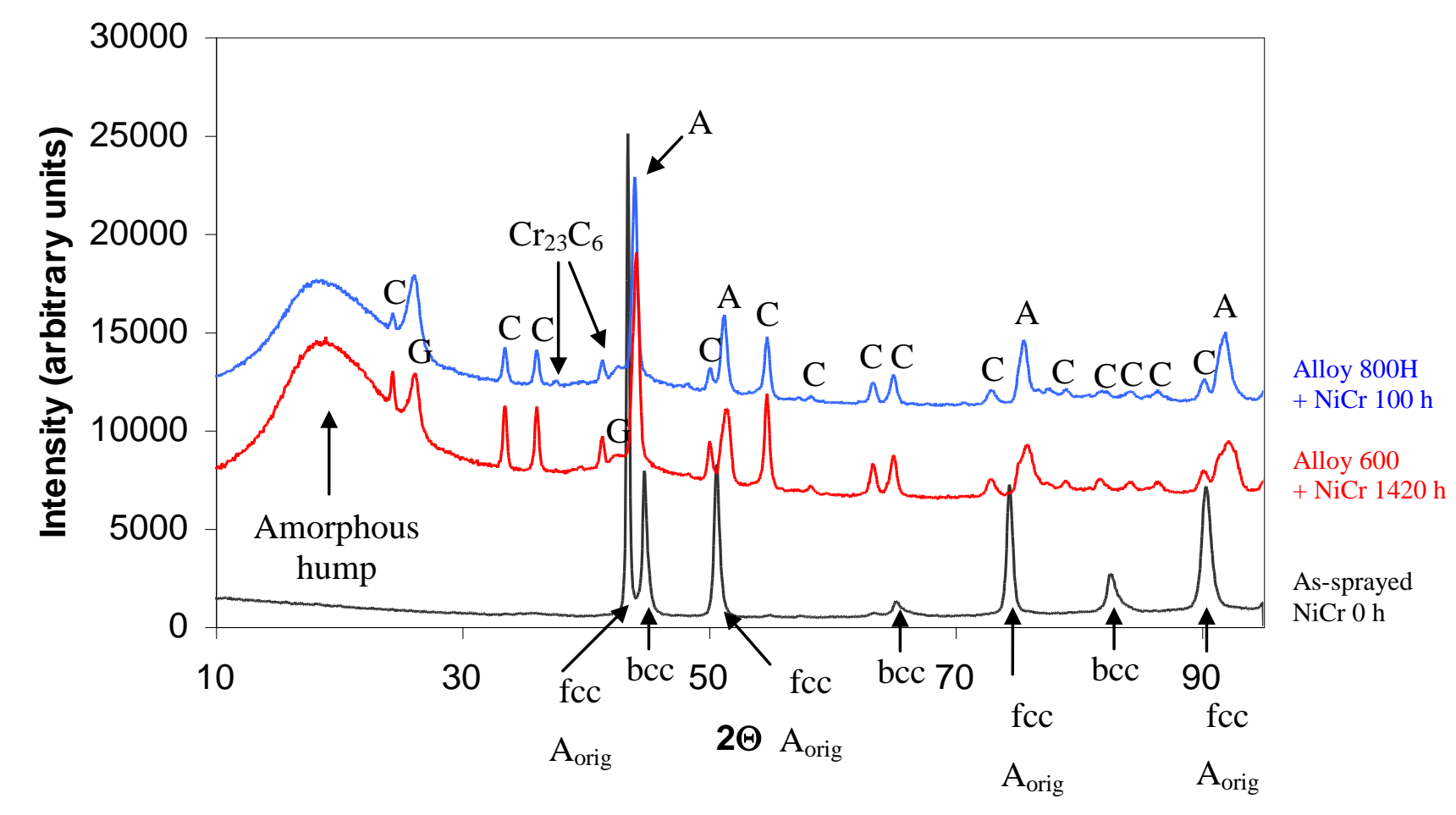

Figure 9 XRD spectra for as-sprayed and exposed $\mathrm{NiCr}$ coated samples. Chromia, and graphite peaks are labelled $\mathrm{C}$ and $\mathrm{G}$ respectively. The original positions of the austenite peaks are labelled $\mathrm{A}_{\text {orig, }}$, the shifted positions after exposure are labelled A. 


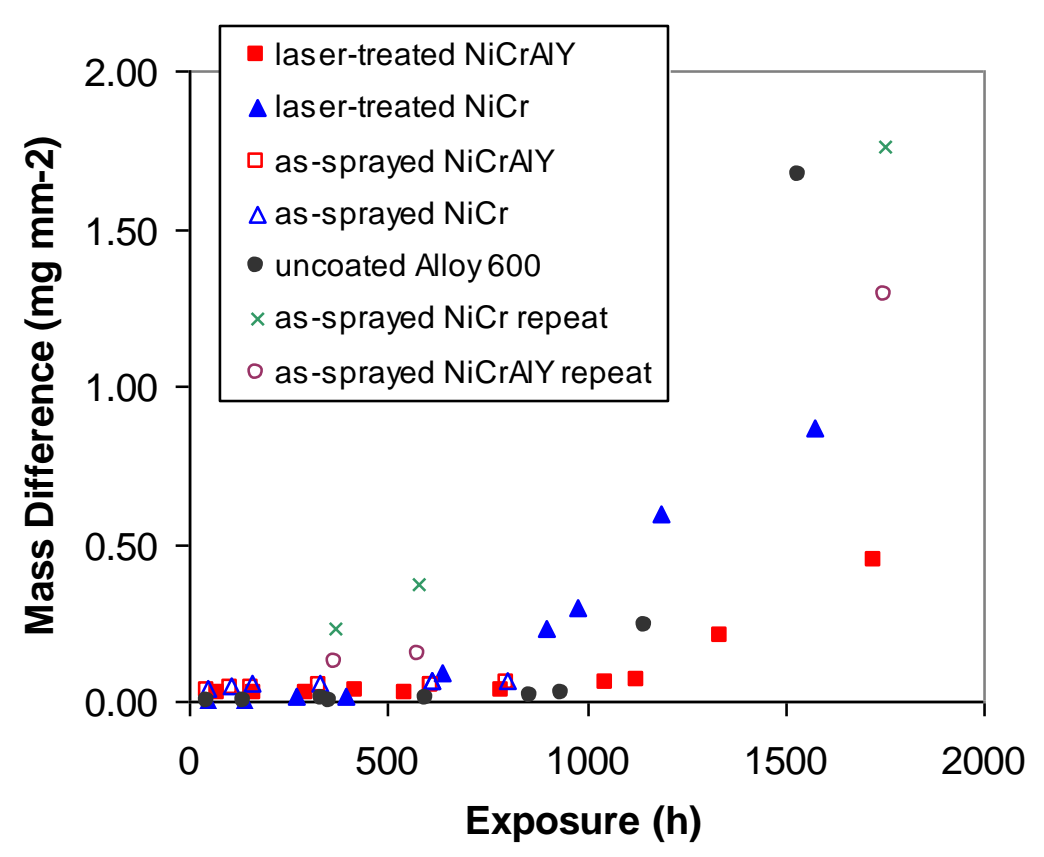

(a)

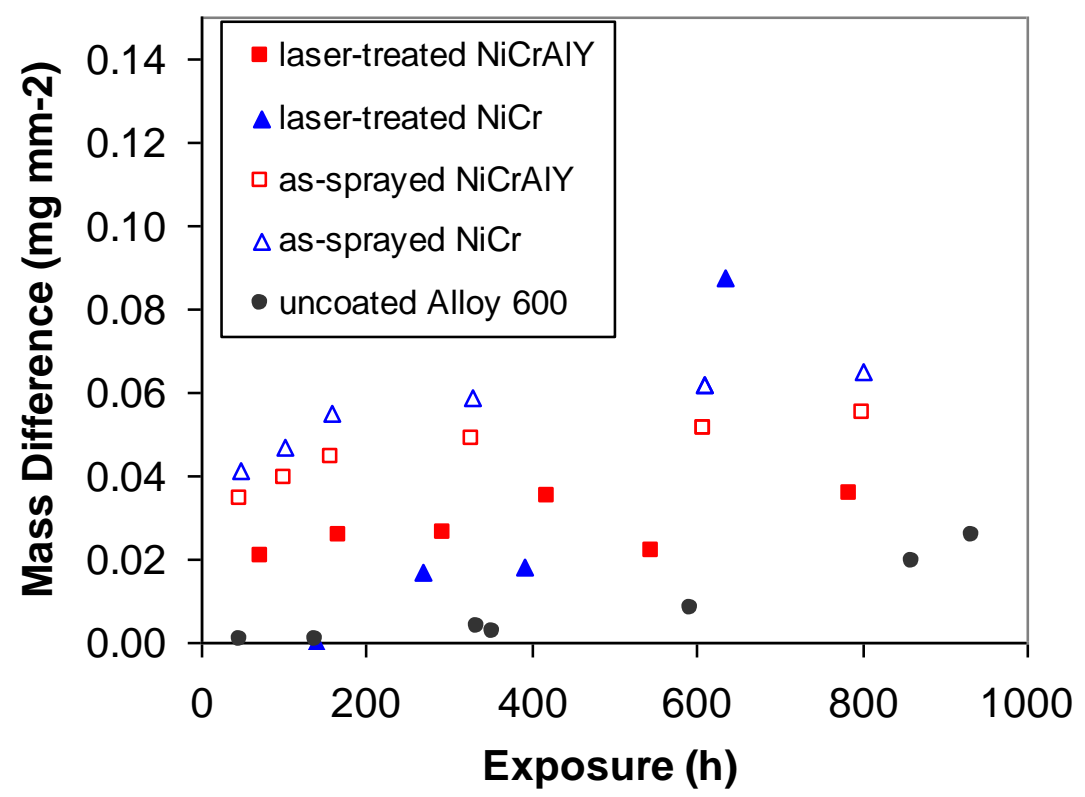

(b)

Figure 10 Mass difference results for Alloy 600 (a) up to $2000 \mathrm{~h}$ (b) up to $1000 \mathrm{~h}$. 


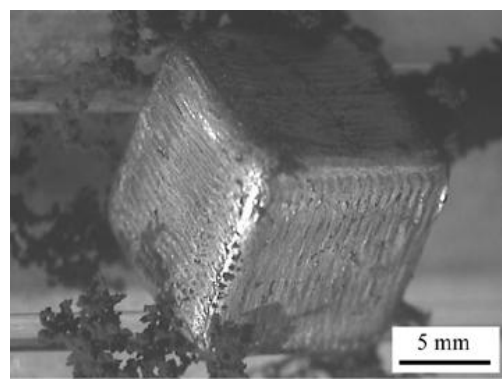

(a)

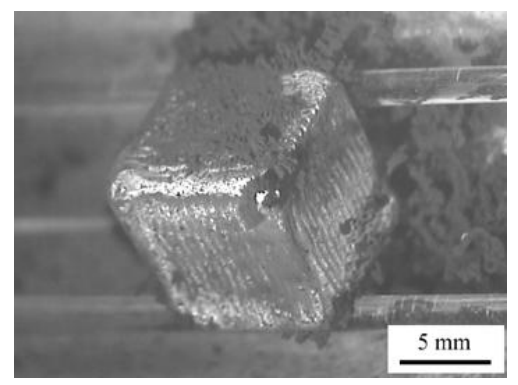

(b)

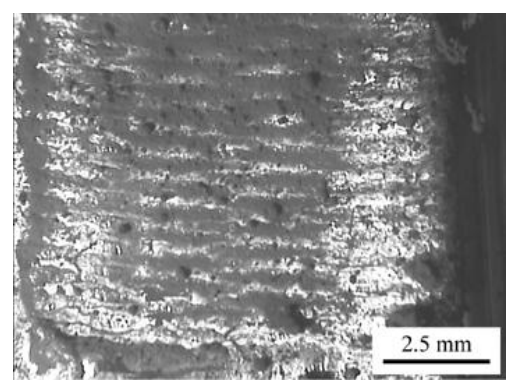

(c)

Figure 11 Optical micrographs of laser melted $\mathrm{NiCrAlY}$ after exposure to the $20 \mathrm{H}_{2} / 80 \mathrm{CO}$ environment at $650^{\circ} \mathrm{C}$ (a) laser melted NiCrAlY-coated Alloy $800 \mathrm{H} 385 \mathrm{~h}$ (b \& c) laser melted NiCrAlY-coated Alloy 600 $1726 \mathrm{~h}$.

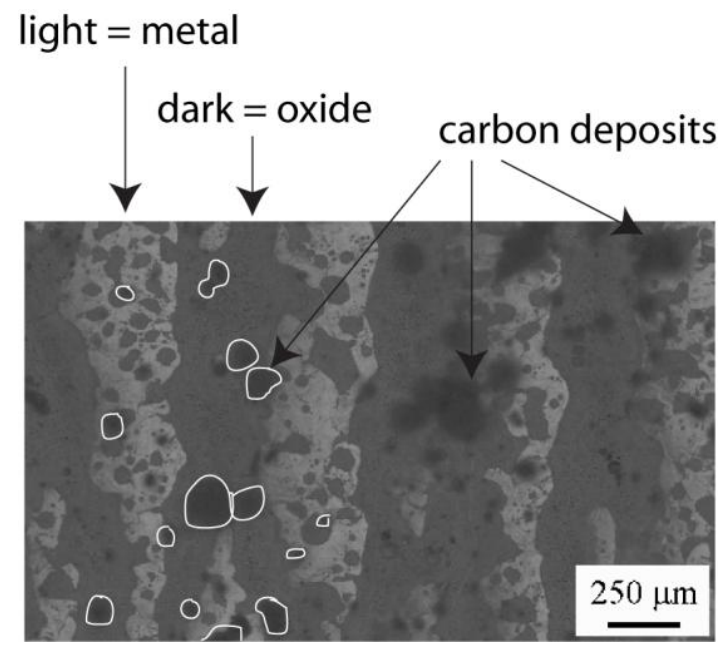

Figure 12 SEM micrograph showing preferential location of carbon deposits on oxide (dark) regions on laser melted NiCrAlY on Alloy 600, $1726 \mathrm{~h}$. Carbon deposits on the left half of the image have been circled in white.

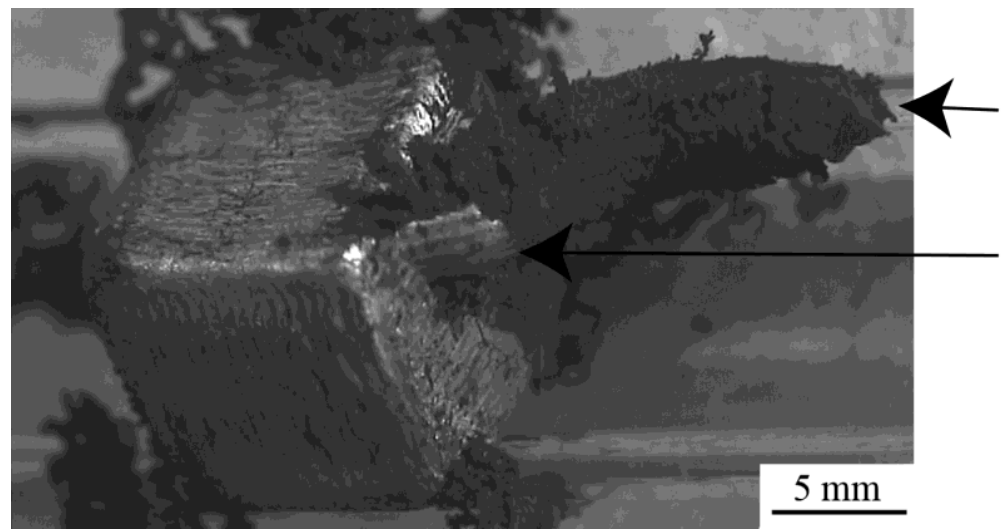

Extensive carbon filament growth Coating spallation

Figure 13 Extensive localised carbon filament growth on laser melted NiCrAlY coated Alloy 800H $385 \mathrm{~h}$. 


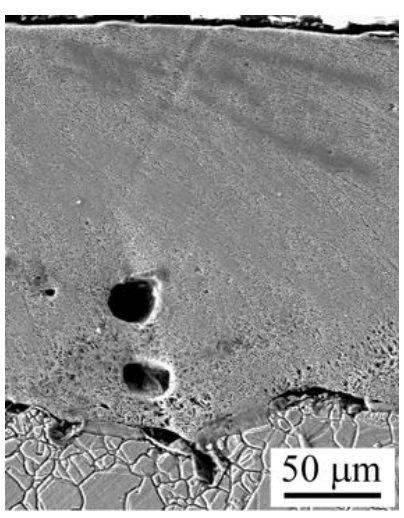

Figure 14 Laser melted NiCrAlY coated Alloy $800 \mathrm{H} 385 \mathrm{~h}$. Embedded $\mathrm{Al}_{2} \mathrm{O}_{3}$ at the interface has resulted in incomplete melting, large pores are present in the laser melted layer.

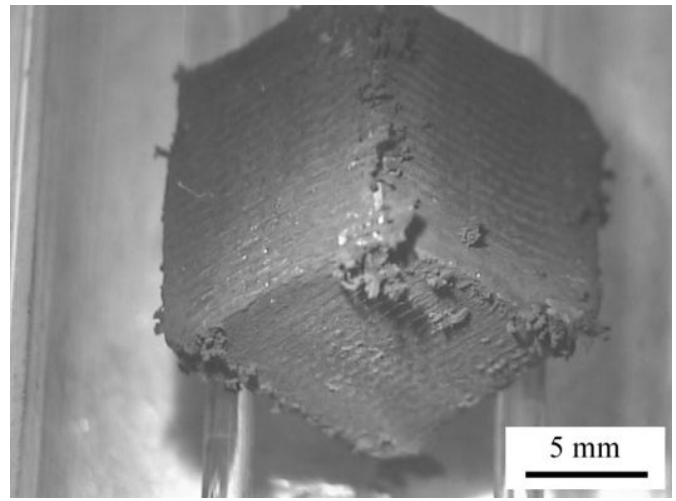

(a)

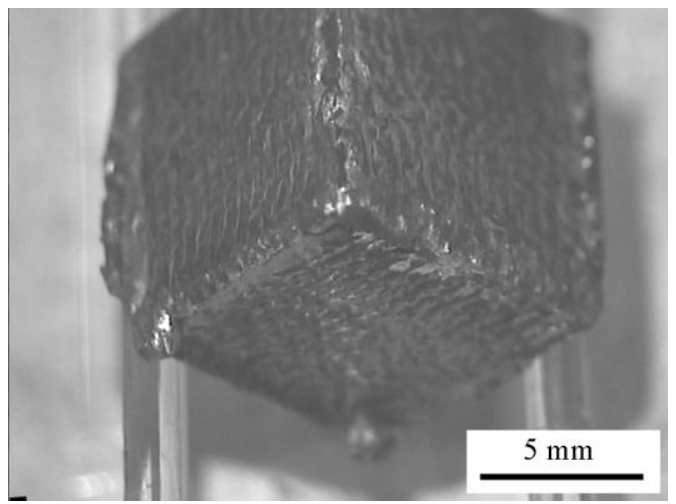

(c)

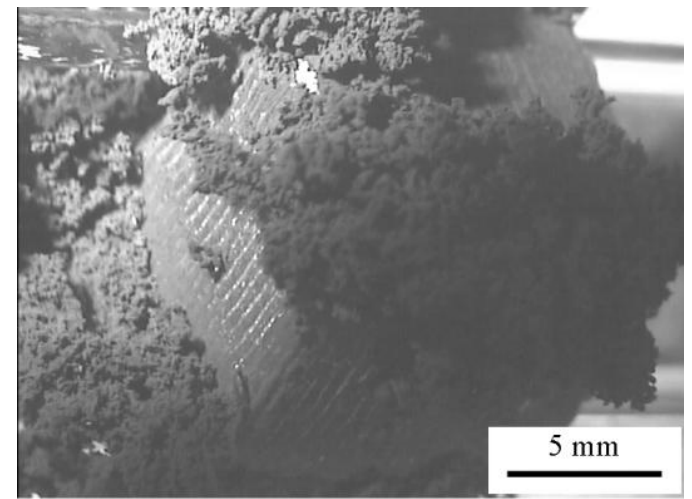

(b)

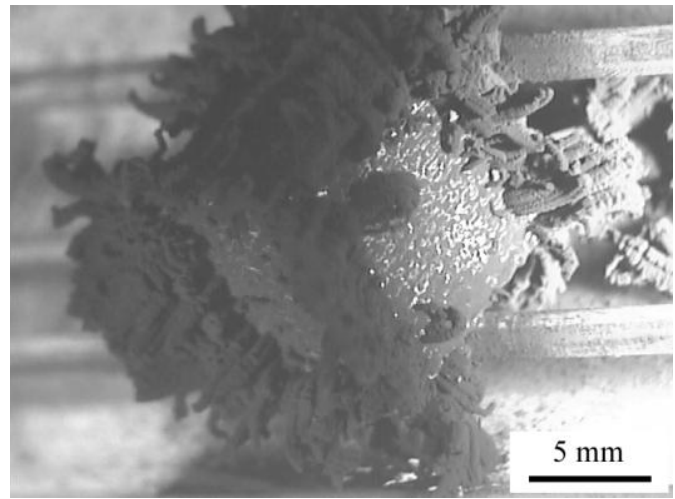

(d)

Figure 15 Laser-treated $\mathrm{NiCr}$ after exposure to the $20 \mathrm{H}_{2} / 80 \mathrm{CO}$ environment at $650^{\circ} \mathrm{C}$.

(a) Laser-treated NiCr-coated Alloy 80047 h (b) 264 h (c) Laser-treated NiCr-coated Alloy 60047 h (d) $1573 \mathrm{~h}$. 

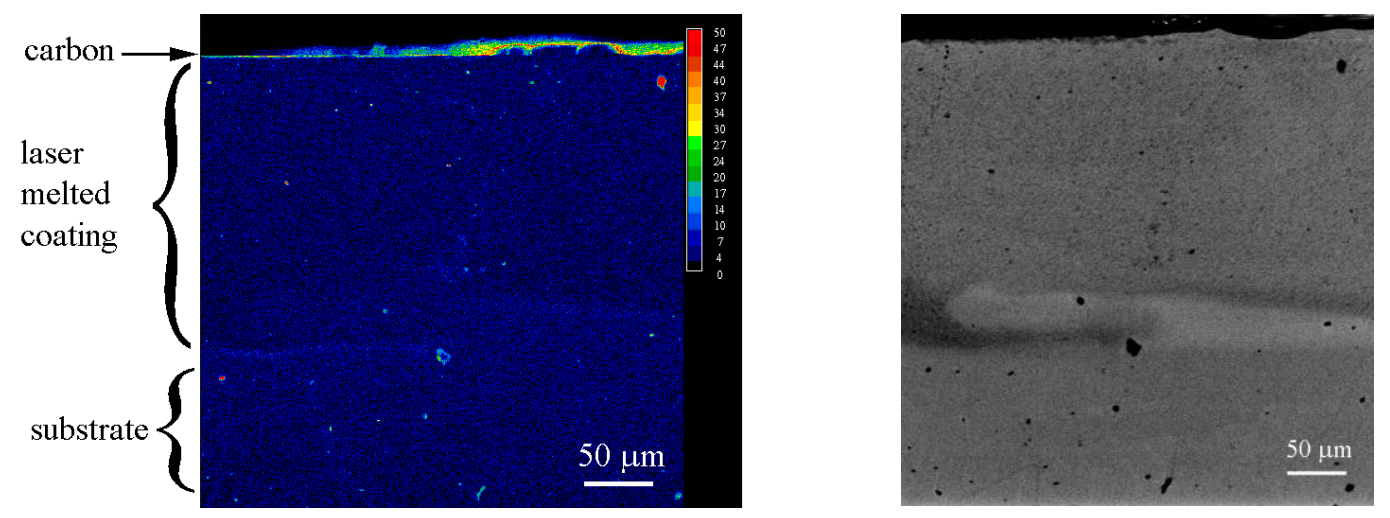

Figure 16 EPMA carbon map and corresponding back scattered SEM micrograph for laser-treated NiCrAlY-coated Alloy $800 \mathrm{H}$ after $310 \mathrm{~h}$ exposure to the $20 \mathrm{H}_{2} / 80 \mathrm{CO}$ environment at $650^{\circ} \mathrm{C}$. 